\title{
The green leaves and the expert: polysemy and truth-conditional variability
}

\author{
Abstract \\ Polysemy seems to be a relatively neglected phenomenon within philosophy of \\ language as well as in many quarters in linguistic semantics. Not all variations in a \\ word's contribution to truth-conditional contents are to be thought as expressions of the \\ phenomenon of polysemy, but it can be argued that many are. Polysemous terms are \\ said to contribute senses or aspects to truth-conditional contents. In this paper, I will \\ make use of the notion of aspect to argue that some apparently wild variations in an \\ utterance's truth conditions are instead quite systematic. In particular, I will focus on \\ Travis' much debated green leaves case and explain it in terms of the polysemy of the \\ noun; and in particular, in terms of the as-it-is and the as-it-looks aspects associated \\ with kind words
}

\section{Keywords}

Polysemy; aspects; Travis cases; meaning alternations

\section{Introduction: polysemy}

Polysemy seems to be a relatively neglected phenomenon within philosophy of language as well as in many quarters in linguistic semantics. Part of this neglect is due to the fact that philosophical and a good part of linguistics semantics have been focused on sentential, truth-conditional, meaning, instead of on lexical meaning for a long time. But another part has to do with the rather implicit commitment of mainstream semantics to one version or another of literalism -i.e., the idea that, barring homonymy, each word-type has a unique simple denotation (such as, typically, a certain individual or a certain -non-conjunctive or disjunctive- property). In general, variations in words' contributions to truth-conditional meanings have been usually treated in one of three ways: (i) as occurrent meanings of indexical expressions; (ii) as meanings resulting from coercion mechanisms, or (iii) as pragmatic phenomena. The indexicalist approach to some words' having different semantic values on different occasions treats these words as covert indexicals, and distinguishes between the standing and the occurrent meaning of an expression: the standing meaning is stable, while occurrent meanings depend on the context of utterance. The mechanism of coercion is also in principle capable of explaining the diversity of word meanings: a word has its own proper 
meaning, but whenever the processor finds a mismatch between that word's type and the type demands of the other words with which it has to compose, the meaning of the word gets adjusted to the compositional demands. Finally, treating variations in word meanings as a pragmatic phenomenon amounts to the view that these variations are best accounted for in terms of pragmatic adjustments of lexical meaning in accordance with hypotheses about the speaker's meaning.

As I say, those cases where it has been found that a certain word provides (or seems to provide) different semantic values in different occasions have been usually treated as cases either of indexicality, of coerced meanings, or of speaker's meanings. These have been the usual tools that the semanticist of the truth-conditional flavor has typically used to regiment meaning diversity. Some other approaches to semantics, in contrast, have highlighted the phenomenon of polysemy. Of especial relevance is cognitive linguistics. Cognitive linguists have for a long time now drawn our attention to the obstinacy and the pervasiveness of polysemy (see e.g., Lakoff, 1987, Brugman, 1988, Taylor, 2003, Cruse, 2004a). But cognitive linguistics has not been alone: linguists from other traditions such as Jackendoff (1992), Copestake and Briscoe (1996), Pustejovsky (1995), and Asher (2011) have also turned their focus to polysemy and have tried to make its study tractable.

Of course, not all variations in the contribution that a word makes to truth-conditional compounds are to be thought as expressions of the phenomenon of polysemy, but it can be argued that many are. That is, it can be argued that there is a genuine and irreducible phenomenon of polysemy such that many words have different but related semantic values in different occasions due to their being polysemous (i.e. not to their being indexicals, not to their meanings being coerced, etc.). To take an archetypical example, it seems that 'book' can have the meaning of text and the meaning of tome not in virtue of 'book' s being an indexical, or in virtue of some coercion or pragmatic mechanism, but, rather, because it is polysemous (see, Pustejovsky, 1995, Cruse, 2004a, Asher, 2011).

Polysemy is usually taken to be a phenomenon where a term has different but nontrivially related meanings or senses (usually all of them having the same status with 
respect to their "being the meaning of the word") ${ }^{1}$. It is customary to think that there are two basic general ways of cashing out this broad characterization: according to the "sense enumeration lexicon", all these different senses are stored in separate representations (see, e.g., Katz, 1972, Foraker and Murphy, 2012). According to the "one representation" approach, all the senses can be traced back to one single representation (see, e.g., Pustejovsky, 1995, Frisson, 2009). However, it is probably too soon to know whether these two alternatives are indeed exhaustive ${ }^{2}$. And it is also surely too soon to know whether any of them (or some other approach) can account for all kinds of polysemy, given that polysemy appears as a multifarious phenomenon and we as yet lack an adequate taxonomy of polysemy.

There is evidence that the "one representation" approach is the best account for at least some cases of polysemy (see, e.g., Frisson, 2009; Klepousniotou, et al., 2012).

However, it is not yet clear what kind of information this representation contains (Frisson, 2009). It may be a summary representation consisting in a set of features common to all senses of the polyseme, or it may be a rather rich representation which makes all senses of the polyseme available. What seems to be clearer is that whereas homonymous meanings are stored in different representations and compete for activation, polysemous senses prime each other, such that each sense facilitates access to the others, which suggests that the storage of homonymous meanings has to be different from the storage of polysemous senses. Although research has been typically focused on regular polysemies until today (see below), it may be that the one representation approach can also account for irregular polysemies (Brocher et al., forth.).

Here I want to make use of the idea that the senses of a polysemous expression may result from differential activations of parts of a rich lexico-conceptual representation. My aim is to explain some particular cases of variations in the truth-conditional content of certain sentential expressions. The kind of lexico-conceptual representations I have in mind, following a suggestion made by Frisson (2009), are exemplified by Pustejovsky's lexical entries for nouns (and the use that, apart from Frisson, other authors make of

\footnotetext{
${ }^{1}$ The meanings of homonyms are related in a trivial way, since they are all meanings of the homonym. The ways in which the senses of a polyseme can be related are numerous: senses can be related by similarity in some relevant dimension, part-whole relations or contiguity of their denotations... ${ }^{2}$ Another option is that some of the senses are stored, while the rest are derived, either by means of rules or by means of pragmatic mechanisms.
} 
them: see below). Pustejovsky (1995) holds that nouns have an associated qualia structure. This qualia structure comprises information about the category the noun refers to vis a vis supercategories and subcategories (formal quale), what the referent of the name is made of (constitutive quale), what it is for (telic quale), and how it came into being (agentive quale), thereby providing a definition of the noun which includes what prima facie would be world knowledge. The parts of this complex and rich definitional structure are differentially activated depending on the context. The qualia structure provides aspects or perspectives (see Cruse, 2004a,b, Paradis, 2004) under which the referent of the noun can be contemplated, and some aspects are more prominent than others in some contexts.

I will hold that this kind of structure, and the idea that we can highlight one aspect or another of it, can account for some systematic alternations in some words' contributions to truth-conditional contents ${ }^{3}$. It has to be noted, though, that Pustejovsky himself does not use qualia structure in the way Frisson et al. use it, to account for polysemy. Pustejovsky (1995, 2001), as well as Asher (2011), are concerned with what they call 'logical polysemy', a special kind of regular polysemy. Regular polysemies are the container-for-content polysemy ('bottle' in 'I drank the whole bottle'), the author-forwork-of author polysemy ('I like Beethoven'), the physical object-for-information polysemy ('the book is entertaining), etc. In these cases, non-zeugmatic co-predication is typically possible, as in 'the book is heavy but very entertaining'. Now, Pustejovsky explains logical polysemy in terms of dot-objects, objects of a special complex type in his type theory formed by an operation on two types which pick up aspects of an object (e.g., the physical object aspect and the information aspect of BOOK, which gives the dot object physical object•information $)^{4}$.

However, some other authors take it that Pustejovsky's qualia structure can play a role in explaining at least some other kinds of polysemy (Frisson, 2009, suggests that it can also explain regular polysemy). Thus, Cruse (2004a, b) has distinguished between facets and perspectives, holding that while Pustejovsky's logical polysemies have to do with facets, which, according to him are clearly discrete senses, there is a maybe more subtle

\footnotetext{
${ }^{3}$ Note that this means that the contributions of polysemous terms to truth-conditional compounds are not classical denotations, but senses or aspects (see Vicente and Martínez-Manrique, forth.). If we think that most words are polysemous, this may imply that we have to revise the current dominant views about how truth-conditions are constructed.

${ }^{4}$ For a list of dot objects, see Pustejovsky (2005). Note that some regular polysemies are excluded from the list.
} 
polysemy which has to do with perspectives, which show a certain level of discreteness, but not independence. These perspectives are provided by the qualia structure. Paradis (2004) uses qualia structures to give content to the notion of "active zones" (Langacker, 1984)

In what follows, I want to use two elements present in these approaches to argue that some apparently wild variations in an utterance's truth conditions are instead quite systematic. In particular, I will focus on Travis' much debated green leaves case (see Travis, 1996, Predelli 2005, Kennedy and McNally, 2010, Hansen, 2011, Rothschild and Segal, 2009, Vicente, 2012). The two elements I will avail myself of are: first, the idea that lexical entries contain, or systematically give access to, rich conceptual information, information which can plausibly said to incorporate world knowledge ${ }^{5}$; second, the idea that contexts can differentially activate parts of this rich conceptual structure thereby highlighting aspects or perspectives ${ }^{6}$.

Probably not all cases of polysemy can be explained as differential activations of different aspects of a conceptual structure, but it seems that many can, in particular if we think about the polysemy of nouns. Think for instance about the 'school' case (Frisson, 2009). 'School' can stand for a building, for the place you take your children to, for the people running the institution, etc. It seems plausible to think that all these senses are stored together, and it is reasonable to think that they form part of a structure, our SCHOOL concept, which can account for the relationship between all these senses. When the context brings to the fore one of these senses, the rest are also primed, but are clearly less activated than the one highlighted. This is, at any rate, what some evidence suggests (see, e.g. Frisson, 2009, Klepousniotou, Titone, and Romero, 2008, Klepousniotou, et al., 2012). Now, if this is characteristic of polysemy, I want to argue that the green leaves case can be treated as an example of polysemy, in particular, as an example of noun polysemy. This position may seem unpromising at first glance ${ }^{7}$, but I think it is worth considering. The results are interesting: we will be able to explain a pattern of meaning alternations while bringing to the fore a subtle kind of polysemy.

\footnotetext{
${ }^{5}$ The account I am about to present does not allow me to differentiate between the hypothesis that the relevant conceptual information is stored in lexical entries and the view that lexical entries simply give systematic access to this information, so in what follows, I will remain agnostic about this issue. However, I do not think that the issue is of particular importance.

${ }^{6}$ My notion of "aspect" is more liberal than Pustejovsky's.

${ }^{7}$ As a referee points out, this general view is not totally novel: it has already been considered (but rejected) before: see Szabó (2001), Gross (2001). For discussion, see Hansen (2010).
} 


\section{Travis cases}

Travis shows that truth-conditions cannot be regimented by linguistic/semantic theory. In his words: "[w]hat words mean plays a role in fixing when they would be true; but not an exhaustive one." (Travis, 1996: 451). That is, he takes his examples to show that, though meaning has to constrain truth-conditions in some way, it falls short of determining them. Whereas meaning is probably a stable feature of words, it cannot determine the contribution that words make to truth-conditional contents. Meaning only puts some constraints on the contribution of words to contents, since there are limits to what a word can be used to refer to (Travis, 2000; pp. $215 \mathrm{ff}$ ). But, apart from that, truth-conditional variation is relatively unconstrained and quite unsystematic. Meaning puts some constraints; the rest depends on the "occasion" of the utterance (Travis, 2008).

Travis's widely discussed examples have been taken to be good illustrations of his skeptical position concerning meaning's role in the determination of truth-conditional contents. However, at least some of the examples fall short of establishing what they are taken to establish ${ }^{8}$. Before I go to consider the famous green leaves case, I want to briefly look at another example, which he discusses at length in his (2000). This is the blue ink case. Travis (2000) tells us that 'the ink is blue' can have different truth conditions on different occasions of use. Someone can assert correctly that the ink is blue just in case the ink looks blue when in its container. But it is also possible to assert correctly that the ink is blue just in case it writes blue, even though the ink may have a black appearance in its container.

Now, this variation may simply be a result of a differential activation of different components of the INK concept (or of the semantic information contained in the lexical entry for 'ink'). Using the Pustejovskyan apparatus in the way Cruse uses it, we can hold that, in the first case, the quale of the ink that is highlighted is its formal quale (ink is_a liquid). In the second case, the quale highlighted is the telic one, roughly: the function of writing. This second reading of 'the ink is blue' -roughly: the ink writes

\footnotetext{
${ }^{8}$ I do not want to hold that all of the examples can be made to fall under some systematic semantic pattern. My purpose is more modest: I want to show that some examples (particularly influential at that) can be treated in terms of a systematic polysemy.
} 
blue- is, as I say, obtained by focusing on the telicity aspect of the entry for 'ink'. The idea is that the color predicate modifies its head in this case in the same way that, for instance, 'fast' modifies 'car' in 'this car is fast'. When FAST is applied to CAR, FAST selects the telicity aspect of CAR, giving as a result the reading this car drives fast ${ }^{9}$.

So the claim is that 'the ink is blue' can convey that the ink looks blue and that the ink writes blue because the lexical entry for 'ink' remits to a complex conceptual structure consisting of various aspects or qualia. When we try to apply the concept BLUE to the concept INK we are offered two possibilities: either BLUE modifies the formal aspect of INK (i.e., ink-as-a-liquid) or it modifies its telic aspect (i.e, ink-as-a-writing-device). In this respect, there is no deep difference between this case and, say, 'I like the book': when we hear or read 'I like the book' we have two possibilities, that LIKE has as its second relatum the physical-object aspect of BOOK, or that its relatum is its informational aspect. That is, an utterance of 'I like the book' is ambiguous between two readings, and it is up to pragmatics to select one of these two possible readings. Similarly, an utterance of 'the ink is blue' is ambiguous, and its ambiguity cannot be resolved but by the pragmatic system. What is interesting, in any case, is that the ambiguity exemplified by both examples is generated by the information contained in (or accessed from) lexical entries.

To see that the blue ink ambiguity is not idiosyncratic we can look at some examples and apparent counterexamples to the idea that, in some cases, color adjectives can modify nouns either in a "formal" or in a "telic" way (i.e. either focusing on the kind of thing the object is or focusing on the function the object has). The cases in point are those where the noun refers to an artifact that is used for coloring surfaces (otherwise, it is obvious that the color predicate cannot modify the telic aspect of the noun: 'red car' can never mean "a car that drives red"). So, we may think of expressions like 'red pen'/'this pen is red', 'green pencil'/'this pencil is green', 'black-and-white printer'/'this printer is black-and-white', or 'blue paintbrush'/'this paintbrush is blue'.

\footnotetext{
${ }^{9}$ Pustejovsky (1995) holds that in cases like 'fast car' the adjective functions like an event predicate. The telic quale specifies an event, and it is this event that is modified by the adjective. However, as Asher (2012) notes, this may be the case of 'quick' rather than of 'fast'. 'Fast' applies not to events associated to telic quale but to dispositions that objects have (e.g., the disposition to drive). It seems to me that there is no reason to be committed to Pustejovsky's particular account. I am content with claiming that just as FAST applies to (the telic quale of) CAR (however that is done), so BLUE can apply to (the telic quale of) INK.
} 
Now, the first three examples seem to support the generalization: a red pen can be a pen that is red or a pen that writes red; a green pencil can be a pencil that is green or a pencil that writes green; and a black-and-white printer can be a printer that is black and white or a printer that prints in black and white. So, if the generalization is something like "color predicates can apply either to the physical aspect of the object or to what the object is for whenever what objects are for is coloring surfaces", here we have evidence in its favor.

However, the paintbrush example seems to be a counterexample. That a paintbrush is blue means that it looks blue, not that it paints blue, even though paintbrushes are for painting, i.e., coloring surfaces ${ }^{10}$. However, there is an explanation for this. Whereas inks, pens, etc. can generate colors -so to speak-, paintbrushes can only transfer them (though see the fn. below). The Pustejovskyan framework seems to offer us two possibilities to cash this difference out: either the difference between paintbrushes and inks, pens, etc. is traceable to their respective constitutive qualia (what they are made of), or it is found in the telic qualia itself. According to the first possibility, we could say that the ink alternation holds only for those concepts which specify that the entity denoted by the noun is constituted in a way such that it can produce colors and transfer them to surfaces either it is a color-producing substance or it has a part -e.g., a pencil lead-, which produces colors); according to the second option, we could hold that the reason for the different behavior of 'paintbrush' and 'ink' is that the telic aspect of 'ink' is not just "it is for writing", but something more detailed that incorporates the information that inks produce colors. Whatever way we take, we have to correct the generalization that we started with. However, the correction is not ad hoc. It makes sense to think that color predicates can systematically modify telic aspects of nouns only if the objects these nouns designate do whatever they do always in one particular color.

In sum, the two alternative truth-conditional contents that an utterance of 'the ink is blue' can have according to Travis can be accounted for in terms of the conceptual/semantic structure associated to 'ink'. Depending on what aspect of this structure comes into focus, we will get one reading or the other.

\footnotetext{
${ }^{10}$ Searching for possible readings of 'the paintbrush is blue', I have discovered that there are now paintbrushes that paint in a particular color, which means that 'the paintbrush is blue' now is as ambiguous as 'the ink is blue' (which is what I actually found in my search in Google). I suggest that we put these new paintbrushes aside for the moment, and think only about good old fashioned paintbrushes.
} 
As mentioned above, Cruse (2004a,b) distinguishes between facets and perspectives. According to him, facets are more autonomous than perspectives, for perspectives are ways of seeing-as. The difference between the 'book' case and the 'ink' case, thus, would be that while the information sense of 'book' is detachable from its physicalobject sense, the artifact sense of 'ink' is not so detachable from its liquid sense. There is an intuition that this distinction tries to capture -we seem to see some difference between the 'book' case and the 'ink' case-, but it is not clear that the distinction has to do with autonomy. Travis (1989) presents another example that can be dealt with the notions we have used, which puts this idea of non-detachability into question. Also, as a referee has pointed out, it is an example that strengthens the idea that the noun, and not the adjective, is responsible for the variation in the blue ink case.

The example is the following: imagine that there is only a small puddle of milk on a fridge's floor. In Scenario 1, A is dejectedly stirring a cup of black coffee. Noticing this B says 'There is milk in the fridge'. In Scenario 2, A has been cleaning the fridge. B opens the fridge door and says 'There is milk in the fridge'. B's utterance in Scenario 1 seems to be false, while that very same utterance seems to be true in Scenario 2. Where does this variability come from? A plausible answer is that, in Scenario 1, the contribution of 'milk' to the truth-conditions of the utterance is its telic aspect, while in Scenario 2, it is its constitutive aspect (its liquid aspect). It is easy to devise a similar example substituting 'milk' for 'ink': just suppose that some ink has been spilled on the floor. In these cases, the two senses of 'ink' and of 'milk' seem to be detached from each other, and it is not easy to see what difference there may be, in terms of autonomy, between the two senses of 'ink' and the two senses of 'book'.

\section{The green leaves}

It seems that the blue ink case is the "easy" Travis case, given the resources that other authors have developed. However, Travis's most debated case is that of the green leaves. According to Travis, an assertion like 'those leaves are green' can be rightly judged to be true in case the leaves are "naturally" green and false if they are "naturally" red. However, the assertion can be also judged to be true if the leaves are naturally red but have been painted green.

Travis (1996) asks us to think of two different occasions where the expression type 'the leaves are green' is uttered by someone called 'Pia'. In the first occasion, Pia is talking 
to a photographer who needs some green leaves for her picture. Pia has decided to paint green some russet maple leaves. Still, in that context, her utterance of 'the leaves are green' is judged to be true. However, then comes along a botanist looking for green leaves. Referring to the very same leaves, Pia says again: "the leaves are green". This time her utterance is judged to be false. Nothing seems to change in the meaning of the uttered sentence, and yet what seemed true in the first context now seems false in the second ${ }^{11}$.

Now, I want to argue that this variation in truth-conditions can be handled in terms of polysemy, and in particular, by means of the strategy of the "differential activation" of senses or aspects stored in, or directly and systematically accessed from, the noun's lexical entry, along the lines of the ink case. The explanation, however, is more complicated in this case.

To begin with, it has to be noted that, according to the account I want to put forward, the polysemous term is not the color predicate. 'Green', in these two circumstances (photographer/botanist), has the same semantic value. 'Green' is plausibly polysemous, and makes different contributions to truth-conditional contents in different circumstances (see Kennedy and McNally, 2010) ${ }^{12}$. However, 'green' does not seem to be varying in content in the different scenarios Travis describes. There is apparently no change of meaning, and 'green' is not behaving as a covert indexical (see Rothschild and Segal, 2009 for the indexicalist approach; Kennedy and McNally, 2010, and Clapp, 2012, for a rebuttal). The relevantly polysemous term, I want to claim, is the noun (at least, I will work under that assumption: its merits can be judged from what this approach can explain).

\footnotetext{
${ }^{11}$ For some formal experimental evidence about these intuitive judgments, see Hansen and Chemla (2013).

${ }^{12}$ Kennedy and McNally hold that in the botanist scenario, 'green' is behaving as a classificatory term and a proxy for another property, in the way 'red' behaves in 'red (traffic) light', or 'negre' (catalan for black) behaves in 'vi negre' (black wine, i.e., red wine). Their argument is that in this scenario 'green' is not gradable. Yet, it seems to me that 'green' is as gradable in the botanist scenario as it is in the photographer scenario. The botanist could take some other, "really" green, leaves, and then claim: 'these leaves are green, you see? And these -referring to some ash leaves- are greener than those -pointing at some beech leaves-. Moreover, it seems that examples of cross-references can be devised, like if we imagine the botanist saying of some pale green leaves that Pia has painted bright green 'those leaves are greener than they (actually) are'. In general, I do not see why 'green' in the botanist scenario should be taken to be a proxy for another property, and I do not find the analogy with the vi negre example compelling. But, as I say, I would prefer that my proposal is judged by its explanatory power.
} 
To develop my position I need to begin by noting that concepts are hierarchically structured, and that subordinate concepts inherit features from their superordinates. 'Leaf' comes marked as a natural kind. In Pustejovskyan terms, its formal quale specifies that it is a natural kind. Now, objects that belong to kinds, in general, and to natural kinds, in particular, have essential make-ups. However, they also have “appearances" at each stage of their existence. By 'essential make-up of an object' I want to refer not just to the constitutive, or essential, properties of the object that belongs to a certain kind, but also to those properties causally connected to them. The essential make-up of a horse is not just its hidden essence, but all those properties -such as having a certain color, having a certain kind of ears, being short or tall...- which causally follow from them. If the hidden essence were the DNA, the essential make-up would be its DNA plus its phenotype (that is, if phenotypes were just expressions of DNA, which does not seem to be the case). The essential make-up of an object usually, but not necessarily, coincides with its original make-up: we can manipulate the "hidden essence" of the object, thereby changing its essential make-up.

"Appearances" do not have to coincide with essential make-ups, or better, the appearance of an object at $t$ does not have to coincide with the essentially grounded appearance of the object (i.e. the appearance the object has when its essence freely expresses itself). This is something that we learn about objects, and it is plausibly connected with the development of the essentialist stance. As it is well-known, we develop deeply grounded essentialist intuitions: we think that, no matter how much a horse is made to look like a zebra by means of "superficial" interventions, we consider it a horse (for the original results, see Keil, 1989; for an extensive discussion, see Gelman, 2003; for an update where it is shown how easy it is for us to categorize in terms of essences, see Frisson and Wakefield, 2012).

In the early childhood (four-five years of age), we begin to distinguish between appearance and reality: the horse looks like a zebra, but it is really a horse. We also begin to distinguish between the essential make-up of an object and the way it appears, i.e., between the object as it is and the object as it looks, or putting it differently, between the properties the object has and the properties it displays. That is, we learn that the non-hidden/apparent properties that an object has at $t$ can be: 
(a) Its properties (i.e. the properties that follow from the free expression of its essence; i.e. part of its essential make-up); or

(b) Properties that the object simply displays at $t$.

Thus, having stripy hair can be a property that the object has (e.g. if it is a zebra) or it can be a property that the object simply displays (e.g., if it is a horse disguised as a zebra). Now, the interesting thing is that if we paint stripes on a horse, and we think about the horse as it is (in terms of its essential make-up), it is not true that it has stripes. However, if we think about the horse as it appears, it is true that it has stripes.

So, it seems that when we think about the properties of an object which belongs to a natural kind we can think about the object in terms of its essential make-up or in terms of its appearance. If we think about the object in terms of its essential make-up, we take it that it instantiates a certain set of properties $\mathrm{P}_{1} \ldots \mathrm{P}_{\mathrm{n}}$; if we think about it in terms of its appearance, we take it that it instantiates a possibly different set of properties $\mathrm{P}_{1} \ldots \mathrm{P}_{\mathrm{n}}$ ' The implication is that, if we find a sentence of the type 'the/this/that $K$ is $F$ ' (where the definite description or the complex demonstrative picks out an object of a certain kind, $K$ is a noun of a kind, and $F$ is an adjective), we may wonder: is ' $F$ ' supposed to apply to the essential make-up of the object or to its apparent look? In the case of colors: when we hear 'the $K$ is green', we may wonder: is green a color that the object has or is it a color that the object displays? There is an ambiguity in utterances of the kind 'the $K$ is $F^{\prime}$ and it is due to the fact that objects can be thought of in terms of their essential make-ups and in terms of their temporary appearances. Prima facie, it is a systematic ambiguity (see below for more development and discussion of examples).

We can perhaps put these ideas in other terms: the kind concept includes the information that objects of that kind have essential make-ups and that they have appearances. When we receive instructions to apply a property to an object of a certain kind, we do not know whether the object is to be thought of in terms of its essential make-up or in terms of its appearance. That is, we do not know which perspective on the object we should take, or how we have to conceptualize it. Do we have to think about the object as the object it is, or just as how it appears? So, I think it can be argued that a common noun such as 'leaf' can contribute with two different perspectives, or aspects, to the truth-conditional contents of the utterances where it occurs. Its contribution can be its essential make-up (leaf-as-what-it-is) or its appearance (leaf-as- 
it-appears). It is in this sense that it can be said that 'leaf' is polysemous, and it is this polysemy which explains the ambiguity of 'those leaves are green'.

Before I go on to elaborate on this point, let me note two things. The first thing to note is that I have been talking about essential make-ups and appearances of objects, while it is possible to wonder whether, in effect, essential make-ups and appearances are properties of the same kind of entity ${ }^{13}$. Focusing on natural kinds, it could be said that only kinds have essences, at least the essences that have been mentioned, while only individuals have appearances, at least in the sense of "current looks" I have been talking about. For instance, many philosophers, following Kripke (1980) believe that whereas hidden properties (such as genetic properties) constitute the essence of kinds, objects and individuals only have essences related to their origins (e.g., it is an essential property of me having been originated from a certain egg and sperm). In this view, individuals do not have hidden essences, and so it may make little sense to speak about essential make-ups of individuals or objects.

However, Kripke's views are challenged by an alternative philosophical theory: sortal essentialism (Wiggins, 1980) ${ }^{14}$. According to sortal essentialism, if $K$ is the fundamental kind of a given object, $O$, (the fundamental kind of $O$ being the answer to the question "what is it?"), then $O$ is essentially of kind $K$. In this view, individuals can be said to have the essences I have been talking about, for if it is essential to a certain horse to be a horse, and it is essential to the kind horse to have a certain DNA, then it is essential to that horse to have a certain DNA. This means that hidden properties characterize the essence of particulars derivatively, but does not mean that they do not give the essence of the individual, or that individuals do not have hidden essences. In this view, then, a particular horse can be said to have an essential make-up given by its hidden essence and the properties causally connected to it.

This is not the place to adjudicate between these two philosophical theories. By introducing sortal essentialism I only wanted to note that it is plausible to defend that it is quite natural to us to think that individuals have essences and essential make-ups as well, that is, that we not only believe that the kind $K$ has a hidden essence, but also that the individual $a$ of kind $K$ has that kind of essence. Note that this implies that for an

\footnotetext{
${ }^{13}$ I thank an anonymous referee for pressing this point.

${ }^{14}$ See Roca-Royes, 2011, for an overview.
} 
individual to be thought as having an essential make-up, it has to be categorized in some way, i.e. it has to be considered as an individual that falls under a certain kind. This in turn means that, unless we enrich its meaning by introducing a kind concept (i.e. the meaning of a sortal noun), an utterance of 'these are green' will not have the ambiguity detected in the original the-leaves-are-green example ${ }^{15}$. The ambiguity of these kinds of utterances, let me insist, is motivated by the role of the noun, which offers two possible construals, aspects, or ways to think about the object.

The second thing to note is the following. I have said that when we think about the properties of an object which belongs to a kind we can think about the object in terms of its essential make-up or in terms of its appearance. However, this is not true without qualifications. If, for some reason, we have to cut one of a horse's legs, it will simply not be true that the horse has four legs (except by thinking about the horse in terms of the type of horse, or animal, it is). The fact is that it seems that we can entertain two different ways in which a property applies to an individual at least when it comes to adjectival properties (i.e. properties denoted by adjectives), i.e., modifiers. If instead of asserting 'that horse has three legs', we say 'that horse is three-legged', it seems that the only reason why we consider the response "no, it's actually four-legged" infelicitous is because it is silly -all horses are four-legged!

I must confess that I do not have a convincing explanation for this fact. One possible explanation is that having four legs and having three legs are not really properties that individuals instantiate: 'the horse has four legs' tells us something about parts and wholes, not about properties and individuals. Another possible explanation is that the ambiguity mostly arises when the properties in question are classificatory. The doubt, or ambiguity, concerning natures and appearances arises, when it arises (see below),

\footnotetext{
${ }^{15}$ For similar reasons, an utterance such as (a) 'the things you are looking at are green' (example provided by an anonymous referee), would not be ambiguous by itself. The definite description does not include any sortal noun; without it, the essence/appearance distinction does not arise. However, it is likely that a hearer of (a), if in front of some leaves, may contextually supply the noun/concept of leaf, thus making the utterance ambiguous. The point, yet, is that if the hearer does not get to think about "the things" as nothing but "things", the utterance would not be ambiguous. This referee also suggests that on the account here defended, where the noun introduces the ambiguity, an utterance such as (b) 'those objects are green' should not be ambiguous either. I am not completely sure about this example, though. Xu (2007) contends that the notion of physical object is a general, maybe primitive, sortal, physical objects having some essential characteristics given by our evolving folk theories about the physical world. I think that (b) would turn out to be ambiguous only if by 'object' we understand something like what Xu and other developmental psychologists have in mind when they speak about our notions of object. It will not be ambiguous if we are using 'object' in the usual, non-committal, way (say, as equivalent to 'thing'). Thanks again to the referee for raising this issue and providing the examples.
} 
mostly when we have to decide whether a certain thing belongs or does not belong to a certain category or can be or cannot be characterized in a certain way ${ }^{16}$.

A number of authors have called attention to the role of aspects in truth-conditional constructions (see Pustejovsky, 1995, Cruse, 2004a, Asher, 2011). In the Pustejovskyan framework (see also Asher, 2011), dot objects are formed by two different aspects. In 'the book is on the top shelf', what 'book' contributes to the truth-conditional meaning of the utterance is the physical-object aspect. In 'the book is entertaining', its contribution is the information aspect. Aspects also contribute to truth-conditional contents in all constructions of the kind 'John as a judge Ps', e.g., 'John as a judge is brilliant' (see Asher, 2011, ch. 7). In these cases, Asher claims that the 'as' construction introduces the intended aspect and coerces the noun into a dot object. As mentioned above, other authors have a more liberal view about aspects, and, as explained, these more "liberal" aspects (i.e. not constituents of dot objects, but, e.g. parts of a qualia structure) do also make a difference in the assignment of truth-conditions to utterances. Aspects are related to our thinking about an object in some particular way. The claim is that these particular ways of thinking about an object do determine the truth-conditional content of our utterances in many cases.

What I want to argue here is that as-it (intrinsically)-is and as-it-looks have the status of aspects linked to some nouns that can also affect truth-conditions. In a nutshell, if we think that a term is polysemous if it can contribute to truth-conditional contents with different aspects (or perspectives or conceptualizations) in different occasions, then it seems it should not sound implausible to hold that 'leaf' is polysemous in the sense explained. And it should not sound implausible to hold that the ambiguity of "those leaves are green' is due to the polysemy of 'leaf' 17 .

\footnotetext{
${ }^{16}$ For the ease of exposition, I will be speaking about properties in general and making general claims about how "properties" can relate to objects depending on how we conceptualize these latter. Perhaps what I say only holds for many properties, but qualifying all my claims would make the reading too convoluted.

${ }^{17}$ Gross (2001, p. 14) has a general argument against the idea that it is the referential variability in the subject term which accounts for the difference in truth-values in the green leaves case. He proposes that we add a second adjective that "effectively fixes the subject's reference while leaving untouched the context-sensitivity of the sentence, as in [The leaves are green and $2 \mathrm{~mm}$ thick]". As both adjectives have to modify the same referent, it cannot be that in one Travis-scenario 'leaves' has one referent and in the other scenario another referent. Now, this strategy is good against those who would claim that in the photographer's scenario the referent of 'leaves' is e.g. the external surface of leaves, while in the botanist's scenario the referent is the inner surface of the leaves, or some other part of the leaves. But this strategy has no force against my proposal. While it cannot be said 'the external surface of the leaves is
} 
This kind of explanation may be applied to other Travis cases such as the round ball case (1996), where we are required to consider a ball hitting a wall: the ball is round, in one sense, but it is not round -rather, it is oval-shaped- if we focus on the shape it is having right when it is in contact with the wall. The ball-as-it-is is round, but the ballas-it-looks is oval-shaped.

Let me now discuss some other similar examples to strengthen the idea that the green leaves case belongs to a pattern and that the explanation provided is not an ad hoc explanation to account for a particular example. Afterwards, I will propose a tentative generalization.

\section{Short stories}

I think there are very many instances where we can observe the kind of ambiguity at place in Travis' green leaves case. Basically, what we have in Travis' original example is that two persons, one interested in the appearance of objects, the other in their essential make-ups, assign different truth-values to the same utterance. The photographer exemplifies the "object-as-it looks" stance; the botanist, let me call him 'the expert', is the paradigm of the "object-as-it-is" stance.

Now, think about the following three examples:

(1) You have inherited a terrible painting from your grandfather. It is a dark and inexpressive portrait of some ugly woman. Everybody that comes to your house says 'that painting is horrible'. However, an expert, who has been looking for a lost Velazquez for a long time, knocks one day at your door, stares at the painting and claims 'Oh! that painting! That painting is beautiful! You'll see...' Then she proceeds to remove a lot of dust, some painting that at some stage was put on top of the original painting, touches here and there, and claims "voilà!" The painting is now, by all lights, beautiful. But note that before she had done his work, the painting was also correctly described as beautiful -that is, provided the utterer of 'the painting is beautiful' had the original painting in mind.

green and 2mm thick' (at least if what is $2 \mathrm{~mm}$ thick is the whole leaves), there is no problem in saying 'the leaves-as-they-are are green and $2 \mathrm{~mm}$ thick' and 'the leaves-as-they-look are green and $2 \mathrm{~mm}$ thick'. Thanks to an anonymous referee for raising this point. 
(2) Your car breaks down and you leave it out in the street. Obviously, the car is not fast, since it is almost impossible to move it. However, a guy comes by and says: "this car is fast". You ask: "the type, you mean?" And he says, "no, this car. It has a wonderful engine. It's really fast. A pity that it's now so broken".

(3) You go to a restaurant and order some seafood you do not know. When you taste it, you don't like it: it's too salty. So you take some water from the jar and pour it over the food. Now you can say with relief "ok., the dish is no longer so salty". However, the maitre corrects you "no, I'm sorry, but the dish is salty"

These examples do not involve natural kinds, so what I am about to say may be philosophically controversial, since we lack convincing theories about essences outside natural kinds. However, our belief in essences seems to be widespread (Bloom, 2010, Gelman, 2013) ${ }^{19}$, so I will assume that it makes sense to talk about the essence of a painting, of a car, and of a dish, without venturing much to say what this essence may consist in. Let me just try with intuitive judgments: what we have in cases (1-3) is that some properties connected to the essence of the entities denoted by the noun have been altered without altering the essence itself. In (i) the aesthetic properties of the painting have been altered without altering its essence -perhaps "having been painted by Velazquez in such and such a way"; in (ii) the speed at which the car can go, a property that results from the way the car is designed, has changed from high to low -or the car is not working at all; and in (iii) the dish, which had a certain taste given its ingredients and the way they were cooked, has lost its original taste ${ }^{20}$. Now, in all these cases we can still truthfully predicate beautifulness of the painting, fastness of the car, and saltiness of the food: the painting in itself is beautiful -only that it has been altered-; the car (token) in itself is fast -only that its engine does not work properly-; the food in itself is salty -only that we have changed its taste. And, obviously, we can rightly assert that the painting is not beautiful, that the car is not fast, and that the food is not salty. In all these cases, like in the green leaves case, you can take an essential make-up look or

\footnotetext{
18 'Salty', both in your mouth and in the maitre's mouth, is intended to mean the same: that the dish is salty (not that you find it salty). The disagreement concerns how you and the maitre think about the dish. ${ }^{19}$ Whereas in Gelman (2013) essentialism only applies to certain categories, including artifacts, according to Bloom (2010, p. 9), essentialism is the "the notion that things have an underlying reality or true nature that one cannot observe directly and it is this hidden nature that really matters." (my italics).

${ }^{20} \mathrm{I}$ assume that the essence of a dish has to do with its ingredients - at least with some key ingredientsand the way these are cooked, and that adding water to a dish does not change its essence.
} 
an appearance look at things. Depending on what perspective you take, you get different truth-evaluations for the very same utterance.

It is, I think, possible to try to extend this kind of explanation to an example taken from Bolinger's (1967) discussion of pre- and postnominal adjectives. Bolinger discusses the following pair:

(a) The visible stars include Capella, Betelgeuse and Sirius.

(b) The stars visible include Capella, Betelgeuse and Sirius.

An utterance of the second sentence can only mean that the stars currently visible include Capella, Betelgeuse and Sirius. However, as Kennedy (2012) notes, (a) is truthconditionally ambiguous: it can have the same truth-conditions as (b), but it can also be understood as being about the stars that are intrinsically visible, such that even if they are not seen at the moment of the utterance -the night is a bit cloudy, or it is sunny-, it is true that they are visible -they can be seen by the naked eye.

Now, whether or not an object is visible depends on how big, how bright, and how close it is. While, in the case of stars, we may think that the first two properties are connected with essential properties of stars, clearly the location of the star is not a result of its constitutive properties. So, it seems, visibility is not a property caused by the hidden essence of stars, which in turn means (see below) that this case does not follow under the green leaves pattern. However, there are chances that the distinction between essential make-ups and appearances play a role in this case as well. This may be wrongheaded, but what suggests this possibility is the way the second reading of (a) is usually paraphrased, namely, that the stars are intrinsically visible (Larson, 1998, Kennedy, 2002). I think this is quite a natural way to express this second reading of (a), which seems to imply that it is natural for us to think that the stars at issue intrinsically, or essentially, have the disposition of been visible. Maybe this is just loose talk, but perhaps we are somehow "discounting" the location parameter in both readings of (a), such that this location parameter is part of the unarticulated background of our thoughts (Perry, 2000) $)^{21}$, and the contrast between the one reading (currently visible stars) and

\footnotetext{
${ }^{21}$ Compare with: the fragility of a glass depends partly on the actual force of gravity of the Earth. However, we do not take into account that parameter when we say 'that glass is intrinsically fragile'.
} 
the other (intrinsically visible stars), has in effect to do with whether we think about the stars in terms of their appearance or in terms of their nature ${ }^{22}$.

Be it as it may, it does seem as though the alternation in the truth conditions exhibited by sentences containing color predicates belongs within a systematic alternation. This systematic alternation consists in that adjectives can modify nouns in two different ways, thus giving raise to two different kinds of truth-conditions. The different kinds of truth-conditions of an utterance of the type 'the $K$ is $F$ ' can be paraphrased as "the $K$ is intrinsically $F$ ", and "the $K$ is apparently/currently $F$ ", or, alternatively, highlighting aspects, as "the $K$ as it is is $F$ ", and "the $K$ as it looks is $F$ ". Apparently, there are obvious counterexamples to the generalization that all utterances of the form 'the $K$ is $F$ ' are ambiguous in the way described. For instance, 'the table is rectangular' cannot mean but that the table's appearance is rectangular. If a table was originally rectangular, but its shape has been changed so that it is now circular, it would be simply false to assert that the table is rectangular. Similarly, if a long rope is cut short, it would be false to assert that the rope is long.

However, these two (and similar) apparent counterexamples can be easily tackled. Arguably, for a property to be ambiguously applied to an entity -either to its appearance or to its essential make-up-, it is necessary that the property be taken to be somehow connected to the essence of the entity (such that the property would be recovered if the entity were allowed to display its proper nature). If the property is not part of the essential make-up of the object, then we should not expect that it can be predicated of this essential make-up aspect.

This is made clear if we compare the following dialogues (1 vs.1', and 2 vs. 2'):

\footnotetext{
${ }^{22}$ This is intended to count as just a suggestion. I am aware that there are many other possible explanations for the truth-conditional variability of (a) -Larson (1998) suggests an ambiguity between individual-level (IL) and stage-level (SL) reading in 'visible'-, but I think a well developed explanation in terms of essences and appearances may stand a chance. On the other hand, I want to note that though the distinction between IL and SL predication can perhaps account for this case -supposing visibility can be an IL predicate at all-, I don't think the distinction is useful in, e.g., the green leaves case. Suppose we adopt the botanist perspective: the only reason why we may say that 'green' is IL, according to that perspective, is because we take it that it is modifying the essential make-up aspect of the leaves. Otherwise, there is no reason to say that the botanist's "green" is individual-level at all. Finally: to the extent that the IL/SL distinction is captured by the ser/estar distinction in Spanish (see, e.g. Maienborn, 2005), the green leaves case cannot be solved by appealing to that distinction: both the botanist and the photographer are right -in their respective situations- if they claim 'las hojas son verdes', while they cannot felicitously say 'las hojas están verdes'. Incidentally, it is not correct to say 'las estrellas están visibles' in any of the situations that would make (a) above true.
} 
(1) [A tells a story to B]

B: Well, that's quite a short story.

A: No, it's quite a long one. I just made it short.

(1') [A shows a rope to B]

B: Well, that's quite a short rope.

A: No, it's quite long. I just cut it short.

A's response in (1) makes perfect sense. But her response in (1') is clearly infelicitous.

(2) [A is a botanist looking for triangular leaves. B has spent the evening cutting leaves with his scissors, making them triangular-shaped]

B: Hey, I have these triangular leaves!

A: I'm sorry, but these leaves are not triangular.

(2') [A is an interior designer. She's looking for triangular tables. B has been cutting all his tables with a saw, making them triangular-shaped]

B: Look! I have many triangular tables here.

A: I'm sorry, but these tables are not triangular.

Again, A's response in (2) makes sense, while her response in (2') does not.

Now, why is this? It seems that the difference between (1) and (1') and between (2) and (2') has to do with the theory-like concepts we have of stories, ropes, leaves, and tables. We think that the length of a story is somehow connected with its essence-whatever the essence of a story is. However, though talking about the essential properties of ropes probably makes doubtful sense, it can be safely said that we do not think that having a determinate length is part of the essential make-up of ropes. The case is clearer with respect to leaves and tables. We think that leaves have essential properties, and that a leaf's shape is causally connected with these essential properties. I do not dare to say anything about the hidden essence of tables -whether they have it or not-, but again it seems that having a determinate shape is just an appearance property of tables, i.e. a property that tables only can display. 
A way to express all these reflections is by means of the following generalization:

(*) If we have an object $O$ of kind $K$, and a property $P$ which is causally linked to the essence that $O$ has in virtue of being a $K$, then 'Det $K$ is $P$ ' -where 'Det $K$ ' refers to $O$ is ambiguous ${ }^{23,24}$.

Whatever we end up saying about the essences of ropes and tables, it is not the case that determinate lengths and shapes are linked to the essence of ropes and tables respectively. Thus, these two examples are not counterexamples to $(*)$.

As it can be seen, the explanation of the green leaves example takes us deep down into issues having to do with the nature of concepts. There are several theories about the structure of concepts. One of them is the theory-theory, which, in one of its renderings, claims that concepts are theory-like structures which track causal relations between properties (see Weiskopf, 2011, for a clear exposition of the theory-theories). Some of these properties form part of the "hidden essence" of the object; the other properties are those properties that directly or indirectly causally depend on the pool of the essential properties. What I have been claiming is that the ambiguity of 'those leaves are green' depends on the fact that the color of the leaves is a property that belongs to the set of properties which are causally connected to the essence of the leaves: it is one of those properties that would be recovered if the essence of the leaf were able to be expressed. In contrast, when the property predicated of an object is not causally connected to its essential properties, or if it belongs to the pool of its essential properties (so that the change in that property implies a change in the essence of the object), the way the adjective modifies the noun is no longer ambiguous. In the first case, the property can only have a display reading; in the second case, the property can only be a has property: if the property changes, the object itself changes ${ }^{25}$.

\footnotetext{
${ }^{23}$ As said above, I am only considering properties introduced by adjectives.

${ }^{24}$ An anonymous referee suggest this other formulation: "Any sentence 'D K is P', where D is a definite or demonstrative determiner, $\mathrm{K}$ is a noun, and $\mathrm{P}$ expresses a property causally linked to the essence of $\mathrm{K}$ itself, or possibly to the essence of the denotation of 'DK' as a K, is ambiguous". I think this alternative formulation of the generalization does capture the idea I want to defend just as well as my own formulation.

${ }^{25}$ Suppose we consider that it is essential to this table to be made of wood, and it is only part of its essential make-up to be brown -brown being the color of the wood. It would be possible to say truthfully of this table 'this table is not brown' if we paint it green, but it would not be possible to say truthfully, of this table, 'this table is not wooden' after we have changed wood for plastic.
} 
In sum: nouns denoting kinds can offer two senses, aspects or perspectives to noun+adjective constructions or 'the $K$ is $F$ ' sentences. The object can be thought of as it is or as it appears. Properties denoted by modifiers apply to any of the two ways of thinking about objects only if they are properties that are connected to the object's essential properties. Thus, to know the possible meanings of a particular noun+adjective construction we need two kinds of conceptual knowledge: first, knowledge of the "is/appears" distinction; and second, knowledge of the theory-like concept associated to the noun. The two are connected: once we start developing the essentialist stance, which consists in conceptualizing kinds in terms of theories, we begin to master the "is/appears" distinction. However, in order to know whether a certain utterance is ambiguous or not, it is not enough to know that a certain object belongs to a kind. You also need to know whether $F$ stands for a property that is causally connected to the essence of that object. And for that, you need to have a theory about the kind to which the object belongs.

There is an empirical prediction that follows from what has been defended. According to this account, children who have not yet mastered the "is/appears" distinction associated to the development of the essentialist stance will understand that 'those leaves are green' means that the leaves look green, and will be unable to understand that 'those leaves are green' can mean that the leaves are green, even if they look e.g., red. It also follows from the account that the "essentialist" understanding of the sentence also requires that the children have the right theory of leaves, i.e., that they believe that the color of the leaves has some connection with their hidden essence. Children who do not have this theory of leaves will be unable to share Travis' intuitions about his two scenarios.

\section{Conclusion}

An influential approach to polysemy has it that lexical entries contain, or give access, to a rich representational structure, and that words can contribute with different aspects, senses, facets and/or perspectives, to truth-conditional meanings. I have been trying to use this general idea to account for what many take to be a purely pragmatic, nonsystematic, phenomenon. According to what I have been defending, Travis' green leaves case falls under a pattern, captured by the generalization (*) above. This pattern, I have suggested, can explained in terms of systematic polysemy, where the nouns 
denoting objects can alternate in their contribution to truth-conditional contents between an object-as-it-is and an object-as-it-appears perspective on their denotations.

\section{References}

Asher, N. (2011) Lexical Meaning in Context. NY: Cambridge University Press.

Bloom, P. (2010). How Pleasure Works: The New Science of Why We Like What We Like. New York: W. W. Norton \& Co.

Bolinger, D. (1967) “Adjectives in English: Attribution and Predication”. Lingua, 18: 134.

Brocher, A., Koenig, J-P, Buckley, K. (forth.) “The retrieval of irregular polysemes leads to fast access and slow integration: Evidence from ERPs".

Brugman, C. (1988) The Story of over: Polysemy, Semantics, and the Structure of the Lexicon. New York: Garland.

Clapp, L. (2012.) "Indexical Color-Predicates: Truth-Conditional Semantics vs. TruthConditional Pragmatics", Canadian Journal of Philosophy 42:71-100.

Copestake, A., and Briscoe, T. (1996) "Semi-productive polysemy and sense extension”. In J. Pustejovsky and B. Boguraev (eds.) Lexical Semantics: The Problem of Polysemy. New York: Clarendon Press. 15-67.

Cruse, A. (2004a) Meaning in Language: An Introduction to Semantics and Pragmatics. Oxford: Oxford University Press.

Cruse, A. (2004b) "Lexical facets and metonymy”. Ilha do Desterro, 47, 73-96.

Foraker, S., and Murphy, G.L. (2012) "Polysemy in sentence comprehension: Effects of meaning dominance". Journal of Memory and Language, 67: 407-425.

Frisson, S. (2009) “Semantic Underspecification in Language Processing”, Language and Linguistics Compass, 3: 111-127.

Frisson, S. and Wakefield, M. (2012) "Psychological essentialist reasoning and perspective taking during reading: A donkey is not a zebra, but a plate can be a clock", Memory and Cognition, 40: 297-310.

Gelman, S. A. (2003). The essential child: Origins of essentialism in everyday thought. New York: Oxford University Press.

Gelman, S. A. (2013). Artifacts and Essentialism. Review of Philosophy and Psychology 4:449-463. 
Gross, S (2001). Essays on Linguistic Context-Sensitivity and its Philosophical

Significance. New York: Routledge, 2001.

Hansen, N. (2010) Radical Contextualism, PhD Dissertation. The University of Chicago.

Hansen, N. (2011) “Color Adjectives and Radical Contextualism”, Linguistics and Philosophy, 34: 201-221.

Hansen, N. \& Chemla, E. (2013) “Experimenting on Contextualism”, Mind and Language 28: 283-321.

Jackendoff. R. (1992) Languages of the Mind. Cambridge, MA: MIT Press.

Katz, J. J. (1972) Semantic Theory. New York: Harper \& Row.

Keil, F. C. (1989) Concepts, kinds, and cognitive development. Cambridge, MA: MIT Press.

Kennedy, C. (2012) “Adjectives” In Russell, G. and D. Graff Fara (eds.), Routledge Companion to Philosophy of Language. Routledge.

Kennedy, C., and McNally. L. (2010) "Color, context, and compositionality”, Synthese, 174: 79-98.

Klepousniotou, E., Pike, G.B., Steinhauer, K., Gracco, V. (2012) "Not all ambiguous words are created equal: An EEG investigation of homonymy and polysemy". Brain and Language, 123, 11-21.

Klepousniotou, E., Titone, D., Romero, C. (2008) "Making sense of word senses: The comprehension of polysemy depends on sense overlap". Journal of Experimental Psychology: Learning, Memory and Cognition, 34, 1534-1543.

Kripke, S. (1980) Naming and Necessity. Cambridge: Harvard University Press.

Lakoff, G. (1987). Women, Fire, and Dangerous Things: What Categories Reveal about the Mind. Chicago, Illinois: The University of Chicago Press.

Langaker, R. W. (1984) “Active Zones”, Proceedings of the Tenth Annual Meeting of the Berkeley Linguistics Society, 172-188.

Larson, R. (1998) “Events and modification in nominals”. In D. Strolovitch and A. Lawson (eds.), Proceedings from SALT VIII. Ithaca, NY: CLC Publications, $145-168$.

Maienborn, C. (2005) “A discourse-based account of Spanish ser/estar". Linguistics 43-1: 155-180.

Paradis, C. (2004) “Where does Metonymy Stop? Senses, Facets, and Active Zones", Metaphor and Symbol, 19: 245-264. 
Perry, J. (2000) “Thought Without Representation”. In The Problem of the Essential Indexical and Other Essays, CSLI Publications.

Predelli, S. (2005) "Painted Leaves, Context, and Semantic Analysis", Linguistics and Philosophy, 28: 351-374.

Pustejovsky, J. (1995) The Generative Lexicon. Cambridge, Massachusetts: The MIT Press.

Pustejovsky, J. (2001) “Type Construction and the Logic of Concepts", in P. Bouillon anf F. Busa (eds.), The Syntax of Word Meaning, Cambridge: Cambridge University Press.

Pustejovsky, J. (2005) “A Survey of Dot Objects”, Authors Weblog (accessed, 1/10/14): ,http://citeseerx.ist.psu.edu/viewdoc/download?rep=rep1\&type=pdf\&doi=10.1.1. 208.7525 .

Roca-Royes, S. (2011) "Essential Properties and Individual Essences”, Philosophy Compass 6/1: 65-77.

Rothschild, D. and Segal, G. (2009) "Indexical Predicates", Mind and Language, 24: 467-493.

Szabó, Z. (2001): "Adjectives in Context", in Kenesei, I. and R. M. Harnish (eds.) Perspectives on Semantics, Pragmatics, and Discourse. Amsterdam: John Benjamins Publishing Company. 119-146.

Taylor, J. (2003) Linguistic Categorization. NY: Oxford University Press.

Travis, C. (1996) “Meaning's Role in Truth”, Mind, 105: 451-466.

Travis, C. (1989) The Uses of Sense: Wittgenstein's Philosophy of Language. Oxford: Oxford University Press.

Travis, C. (2000) Unshadowed Thought. Cambridge, MA: Harvard University Press.

Travis, C. (2008) Occasion-sensitivity. Oxford: Oxford University Press.

Vicente, A. (2012) “On Travis Cases”, Linguistics and Philosophy, 35 (1):3-19.

Vicente, A. and Martínez-Manrique, F. (forth. 2014) “The big concepts papers: a defence of hybridism". British Journal for the Philosophy of Science

Weiskopf, D. (2011) “The Theory theory of concepts". Internet Encyclopedia of Philosophy. (Published online, April 29, 2011)

Wiggins, D. (1980) Sameness and Substance. Oxford: Basil Blackwell.

Xu, F. (2007) "From Lot's Wife to a Pillar of Salt: Evidence that Physical Object is a Sortal Concept". Mind and Language, 12: 365-392. 
